\title{
Políticas para e com a juventude
}

EQUIPE EDUCAÇÃO E COMUNIDADE
Não sabemos como é ser jovem hoje. Saber o que foi ser jovem não basta.

Educador do Programa Jovens URBanos ${ }^{1}$

\section{preocupação pública com a juventude é tema recorrente} na mídia - sempre presente nas falas de políticos, governantes, juízes, pesquisadores, artistas.

No geral, vocalizam as relações entre jovem e violência, consumo, precariedade educacional e desemprego.

O que o noticioso pouco destaca é a presença de um processo intergeracional que a globalização econômica acirrou, no qual as estruturas de oportunidades geradas pela sociedade são cada vez mais restritas para a juventude, particularmente aquela com pouco poder de compra.

(...) Eu acho que muitos encaram a juventude como uma fase de transição, não como um momento específico da vida que tem as suas características, que tem as suas questões. Uma coisa que eu escuto muito falar é da maturidade do jovem, que o jovem é imaturo. Mas é imaturo com relação a quê? É imaturo com relação a minha maturidade porque sou uma mulher com uma história de vida.

Não sabemos como é ser jovem hoje. Saber o que foi ser jovem não basta. Essa rotulação de que o jovem é o problema não pode continuar. 0 fundamental é que possamos oferecer condições para que eles possam fazer suas escolhas... desenvolver suas potencialidades. 
Comentários de educadores do Programa Jovens Urbanos

O tema da juventude entrou na agenda pública, porém não se converteu em política pública.

Qualquer que seja a política pública, ela é sempre objeto de disputa, quer seja na sua formulação, quer seja na sua operacionalização. Só se torna política pública, o que é problematizado socialmente. Uma questão pode estar incomodando a sociedade, mas se não ganha visibilidade e não afeta diretamente os setores mais interessados, dificilmente ela se torna uma política pública. (AGUIAR: 2007)

A política para e com a juventude se insere em um cenário de disputa.

Como pré-anúncio de uma política de juventude, nesta última década, alguns processos avançaram no País. Novas institucionalidades foram criadas:

- Estudos realizados para conhecer e mapear "o estado da arte” em relação às ações públicas voltadas à juventude.

- Constituição de Secretaria Nacional de Juventude, vinculada à estrutura da Secretaria-Geral da Presidência da República, responsável pela formulação da Política Nacional de Juventude.

- Constituição do Conselho Nacional de Juventude, com representantes de diversos segmentos jovens.

- Conformação de leis de proteção e desenvolvimento da juventude brasileira - Estatuto da Juventude, em tramitação no Congresso nacional.

No entanto, esse pré-anúncio não alterou a vigência de projetos pontuais, em sua maioria, conduzidos pela própria sociedade civil. Permanecem no circuito da ação social.

A mais recente iniciativa governamental se anuncia com o Programa Nacional de Inclusão de Jovens - Projovem voltado para as grandes cidades. É ainda um programa e não uma política.

\section{Números eloqüentes e preocupantes}

A juventude (recria) instrumentaliza diferentes linguagens, enfoques para manifestar seus anseios e insatisfações. Assume faces diferentes de acordo com as condições materiais e culturais que a cercam, de acordo com o território em que se encontram. (CASTRO E ABRAMOVAY, 2002, p. 28)
Dos 3,2 milhões de estudantes que terminaram

o ensino médio em 2000, apenas 1,2 milhão chegou à universidade. Em 2006 cerca de 839 mil (2,4\%) jovens eram analfabetos, 65\% deles concentravam-se na região Nordeste (IBGE / $P N A D, 2006)$.

O grupo juvenil, do ponto de vista demográfico é o mais expressivo da população brasileira:

- Os jovens entre 15 e 24 anos somam 34 milhões, o que representa $1 / 5$ da população brasileira (IBGE / PNAD, 2006).

Dados referentes à escolaridade dos jovens sinalizam para um grave déficit:

- apenas $52 \%$ dos jovens concluem a educação básica e levam em média 12,2 anos para fazer essa trajetória (IBGE/PNAD,2001).

Dos 34 milhões de jovens brasileiros, apenas 16,2 miIhões encontram-se nos bancos escolares, o que corresponde a menos da metade do total desse grupo etário.

Entre os jovens adolescentes de 15 a 17 anos, é maior a proporção de estudantes ( $82 \%$ deles estão na escola), embora metade (40\%) ainda esteja matriculada no ensino fundamental, e $57 \%$ no ensino médio.

Dos 3,2 milhões de estudantes que terminaram o ensino médio em 2000, apenas 1,2 milhão chegaram à universidade. Em 2006 cerca de 839 mil $(2,4 \%)$ jovens eram analfabetos, $65 \%$ deles concentravam-se na região Nordeste (IBGE / PNAD, 2006).

Também é preciso mencionar o déficit no acesso a esportes, lazer, cultura e tecnologia de informação: em 2001, cerca de $21 \%$ dos municípios brasileiros não tinham biblioteca pública, $92 \%$ não tinham cinema e $24 \%$ não tinham um ginásio poliesportivo.

Acrescente-se a esse contexto o fato de que, em nossas regiões metropolitanas, a população juvenil vive em situação de vulnerabilidade e convive com o contexto de violência urbana.

A educação como prioridade para este segmento etário fica subsumida. Esse fato é claro quando se observam ainda hoje as altas taxas de distorção idade/série, o 
abandono escolar e a forte restrição de oportunidade de ingresso ao ensino médio público. É comum nesse cenário o lamento em torno da redução drástica da oferta de postos de trabalho para os jovens de 16 a 21 anos.

Colocar a centralidade no emprego e não na educação é um desatino conservador da política pública brasileira.

Essa teimosia mantém-se cega à excedência cultural presente na sociedade contemporânea que desloca nosso olhar desejante para outras oportunidades que não só a inserção no mercado de trabalho.

Tal teimosia não reconhece também a baixa efetividade da opção pelo trabalho para jovens, seja pelas características do grupo juvenil - fluidez emocional, transitoriedade e tempo de experimentação - seja pelo próprio mercado de trabalho fortemente restrito e informal.

É nessa leitura que se compreende o fracasso do programa nacional Primeiro Emprego, lançado pelo governo federal em 2003, relançado em 2004 e extinto por total falta de adesão em 2006. ${ }^{2}$

Os jovens têm dificuldade em permanecer muito tempo nos primeiros empregos. Para entender por quê, basta comparar a procura de emprego à busca do casamento. Em geral, os jovens não se casam com o primeiro namorado. Eles não têm dificuldades para encontrar um namorado, mas seus primeiros romances são curtos.

Com o passar do tempo, os jovens ficam experientes, encontram alguém e formam, então, um par mais permanente. A proporção de "avulsos" entre os jovens é mais alta do que entre os mais velhos não porque os jovens não namoram, mas porque os namoros são mais curtos. Há sempre muitos jovens "procurando emprego" e namorados. E é bom que seja assim, pois a rotatividade nos romances da juventude acaba produzindo melhores encontros definitivos.

Com o emprego é a mesma coisa. Os jovens "rodam" mais porque experimentam as empresas e são experimentados por elas. Isso é bom. Com o tempo, encontram uma vaga e criam um vínculo mais duradouro.

Hélio Zilberstein, Jornal Folha de S.Paulo, 29/3/03, P.A-3.

A taxa de desemprego entre os jovens, nos grupos de 15 a 17 anos e 18 a 24 anos, está em torno de $8,8 \%$ e $12,5 \%$, respectivamente.

No grupo de 25 a 49 anos é de $5 \%$, reduzindo para $1,4 \%$ nos de mais de 50 anos (IBGE/PNAD, 2006).

Os estudos indicam que as taxas de desemprego juvenil são elevadas tanto no Brasil como no restante do mundo. Alem da condição etária (fase de experimenta- ção e rotatividade) outros fatores contribuem para isso, incluindo o de expansão da economia.

O Brasil ainda patina na formulação de políticas e programas sociais voltados à juventude; os déficits de oportunidades educacionais e culturais para sua juventude chegam a ser dramáticos.

Estudos recentes da Fundação Getúlio Vargas - FGV indicam que "a variável anos completos de estudo justifica, sozinha, $39 \%$ da desigualdade, acima de qualquer outra variável censitária”’

A análise desses dados aponta para a necessidade de investimentos em programas para a juventude que tenham como efeito o aumento de anos de estudo, buscando interromper o ciclo da desigualdade que empurra os jovens para o trabalho precário e desqualificado.

Como lembra Dowbor,

O século XXI será o século da informação, da sociedade do conhecimento. Não há nenhum futurismo pretensioso nesta informação, e sim uma preocupação com as medidas práticas que se tornam necessárias e cujo estudo deve figurar na nossa agenda (2001, p.133).

A sociedade do conhecimento em que vivemos absolutamente tomada por tecnologias exige mais que aprendizagens específicas. Nossa sociedade clama por uma educação capaz de formar jovens para o tempo e espaço societário hodierno; para apoiá-los no difícil processo de inclusão na sociedade complexa, as aprendizagens não são apenas cognitivas, mas, sobretudo, socioafetivo-culturais.

A integralidade da pessoa humana abarca intersecção dos aspectos biológico-corporais, do movimento humano, da sociabilidade, da cognição, do afeto, da moralidade, em um contexto tempo-espacial. Um processo educativo que se pretenda integral precisa promover o desenvolvimento de todos esses aspectos de modo integrado, ou seja, a educação visaria à formação e ao desenvolvimento humano e não apenas ao acúmulo informacional (Bernadete Gatti, apud Isa M. F. Rosa Guará, 2006, 16).

As aprendizagens se fazem com ação e na ação. A apropriação e expansão de conceitos, atitudes, valores, e competências pessoais e sociais ocorrem em contextos intencionais, quando necessidades e propósitos de aprendizagem são significativos, partilha- 
dos pelos envolvidos, apresentam sentidos reais e exigem participação.

Em síntese, um projeto educacional inclui, para além do aumento da escolaridade, a aquisição de outras habilidades no plano da sociabilidade, da ampliação de seu repertório cultural, de participação na vida pública, da fluência comunicativa e domínio de outras linguagens de forma a se sentir competente para acessar as riquezas societárias e obter ganhos de pertencimento e reconhecimento de sua cidadania.

Assim é que cultura e participação na vida pública são mediações privilegiadas no desenvolvimento pessoal e social de jovens.

Os jovens constroem projetos de vida cunhados na incerteza e desconfiança frente às certezas; obtêm ganhos de aprendizado na experimentação e na circulação nos diversos e múltiplos espaços e territórios a que têm acesso, obtêm ganhos de aprendizados compelidos na e pelo apelo da sociedade da excedência cultural, desenvolvem aprendizados quase espontâneos na oferta glamorosa dos hipertextos e multimídia que viabilizam comunicação e informação.

\section{Circulação e aprendizagem}

\section{Nossa juventude se insere em uma sociedade marcada}

pela complexidade. É uma sociedade ao mesmo tempo local e global; uma sociedade da escassez e da abundância que mantém enormes desigualdades sociais; uma sociedade de forte apelo ao consumo de massa que sobrepõe o desejo à necessidade ; uma sociedade do conhecimento, da informação e da contínua inovação tecnológica.

Uma sociedade que se desfez do modelo tradicional de emprego e trabalho e conclama os cidadãos a reinventarem o trabalho seja pela indução contínua à novas ocupações, seja por modelos de emprego autônomo, virtual, precário.

Os jovens de hoje ampliaram suas expectativas de realização e se frustram continuamente pela decalagem cada vez maior entre expectativas e reais possibilidades.

Para compreender e atuar nesta sociedade, Morin nos convida a adotar a idéia de um pensamento complexo. Isto é, um pensamento que religa, porque contextualiza e integra, e dialógico, porque relaciona antagonismo e complementaridade, aceitando a tensão entre certeza e incerteza.

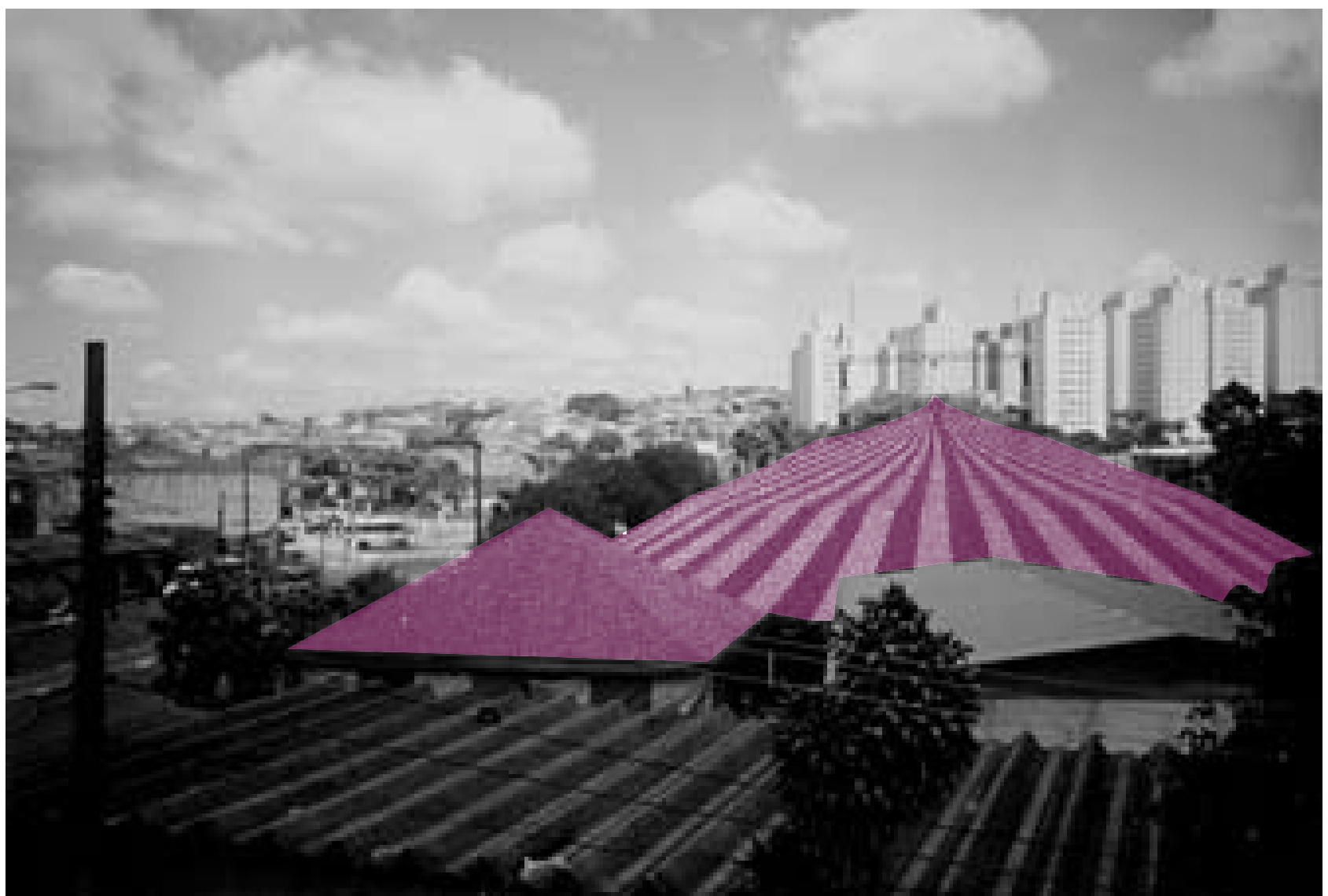


0 jovem precisa ter inserção em três ordens institucionais: estado, comunidade e mercado - que são consideradas centrais na geração de "estruturas de oportunidades".

0 processo de emancipação no qual os jovens se encontram, implica uma interação ascendente com as gerações que os precedem - os adultos. Enquanto estes últimos já estão integrados à dinâmica social, os jovens carecem de incentivos para facilitar sua incorporação a essa dinâmica, até porque paradoxalmente essa incorporação é chave para assegurar a reprodução biológica e social de uma sociedade dominada por adultos.

A constante tensão entre o mundo dos adultos e o mundo dos jovens tornou-se constitutiva da maioria das sociedades atuais, ainda que as características de tal conflito obedeçam a condições estruturais e sedimentações culturais particulares (Cepal/Celade, 2000² Cubides, Laverde e Valderrama, 1998).

Essa tensão resulta visível em aspectos tais como as lógicas institucionais que privilegiam o mundo adulto, as diretrizes oficiais da escola - que ignoram o conhecimento que os estudantes adquirem em sua vida cotidiana -, a racionalidade de uma sociedade de mercado que só vê nos jovens potenciais consumidores (e não produtores).

E essas lógicas colidem - às vezes de maneira violenta - com novas sensibilidades, formas de se relacionar, de conhecer e experimentar o mundo e de construir seu futuro.

Por isso mesmo, não há um único programa que dê conta dos interesses e expectativas descentradas dos jovens. Combinações programáticas ricas e diversificadas dependem da constituição de espaços rede e programas rede que viabilizem circulação formativa e autoaprendizagem.

Essa linha de reflexão alerta para a desigual distribuição dos recursos disponíveis entre os diferentes grupos etários, que favorece os adultos incorporados à população ativa, e para os quais se orientam quase todas as políticas sociais relevantes.

Essa questão sugere a importância de considerar o contexto em que se situam os jovens até mesmo porque estariam por definição, entre os grupos excluídos e com restrições institucionais aos bens, recursos e posições de poder na sociedade.

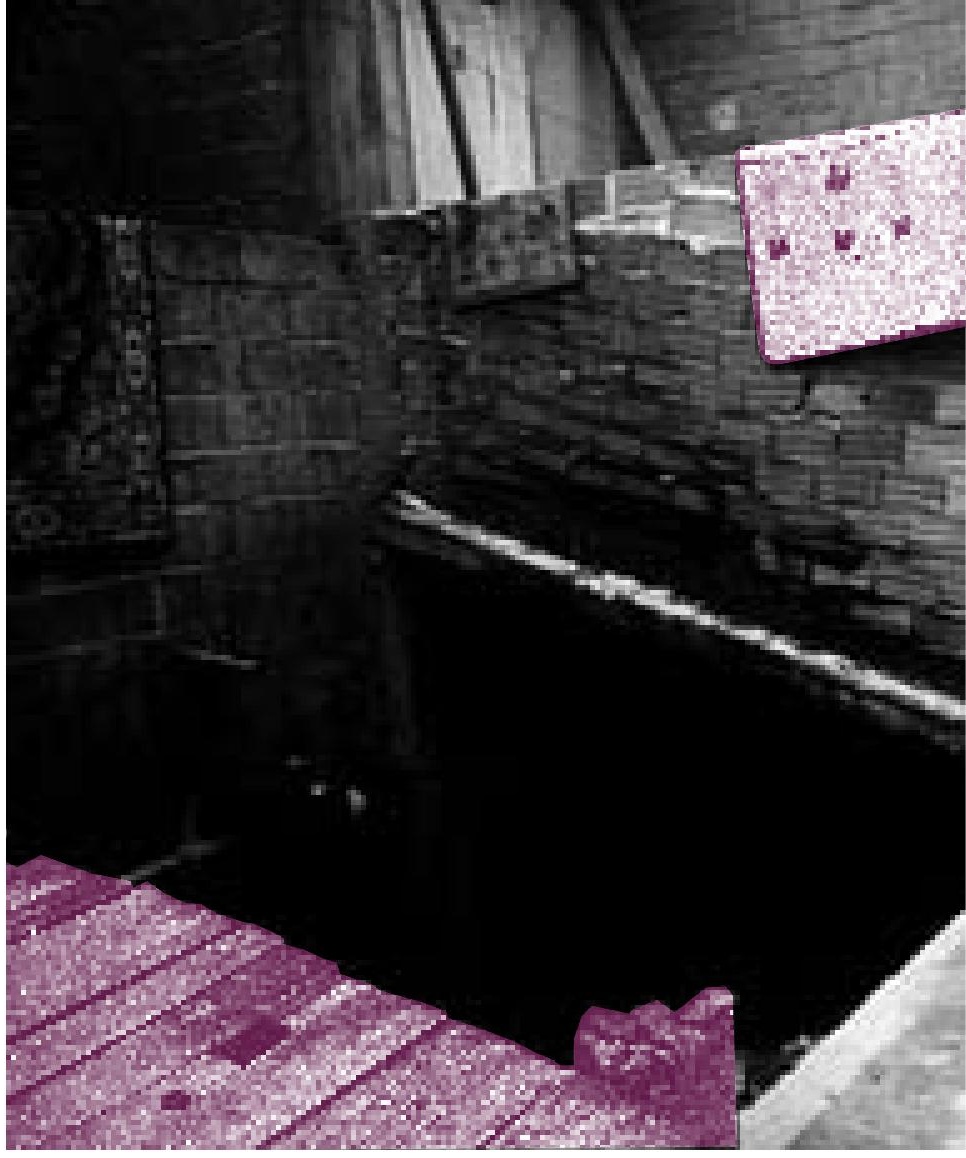

\section{REFERÊNCIAS}

DOWBOR, Ladislau. Tecnologias do conhecimento: os desafios da educação. Petrópolis: Vozes, 2001.

CEPAL/CELADE (2000), Juventud, población y desarrollo en América Latina y el Caribe, Santiago de Chile, LC/L.1339 e Cubides, H., M. Laverde y C. Valderrama (1998), Viviendo a toda: Jóvenes, territorios culturales y nuevas sensibilidades, Santafé de Bogotá, Universidad Central, Siglo del Hombre.

GUARÁ, Isa Maria F. Rosa. É imprescindivel educar integramente. In Cadernos CENPEC. Educação Integral. Ano 1, nํ2, 2006.

CASTRO, Mary Garcia e ABRAMOVAY, Miriam. Por um novo paradigma do fazer políticas - políticas de/para/com juventudes. Revista Brasileira de Estudos de População, v.19, n.2, jul./dez. 2002.

\section{NOTAS}

1 Os comentários dos educadores foram feitos em grupo focal e, por isso, as falas não são identificadas.

2 Felícia Madeira insiste que este dado é compreensível seja pelo comportamento do mercado que recruta trabalhadores mais adulto, seja pelo com portamento do jovem. Os dados comprovam que a tendência de inserção no mercado de trabalho atinge a "normalidade" dos índices de absorção de mão-de-obra a partir dos 25 anos.

3 Ensaios - Revista conjuntura Econômica, 2000-2003. 


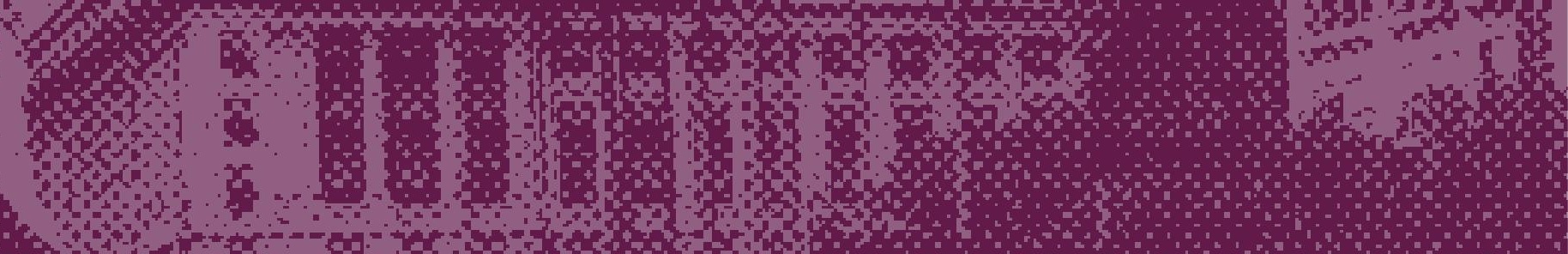

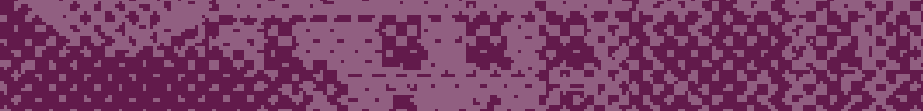

16.

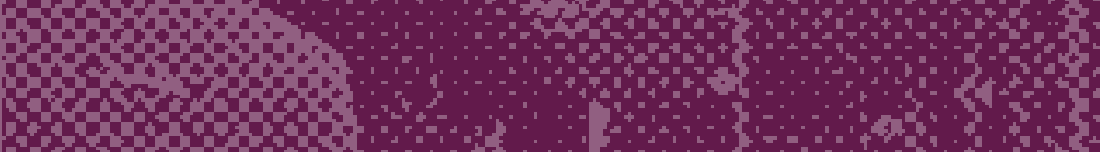

1

然

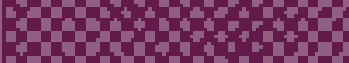

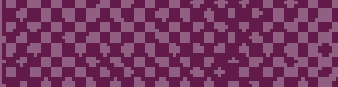

.

.

.

,

,

,

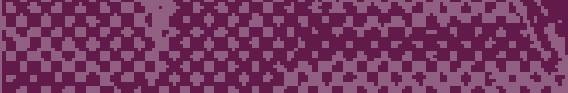

40,48

208

2018

5, (2) (1) mogn.

$3+2$

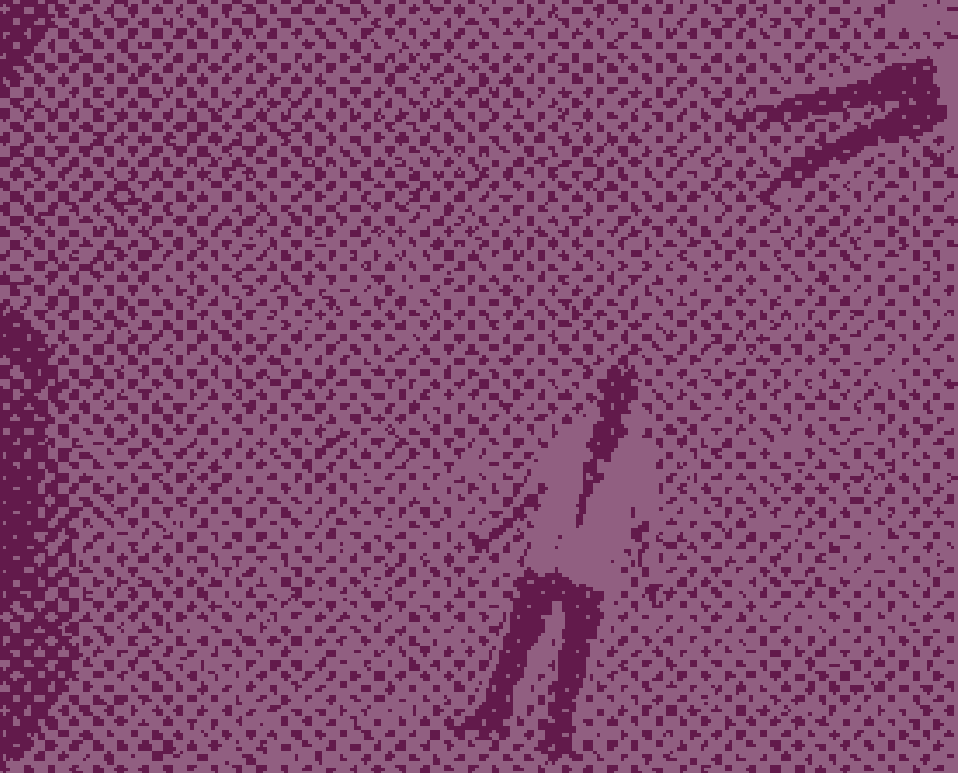

$6+4$

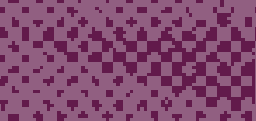
$48+$

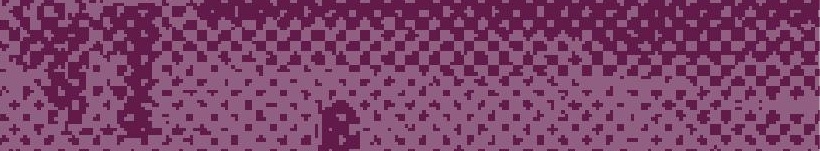

